\title{
THE DOUBLE ROLE OF THE STING OF THE HONEY-BEE.*
}

Very important and highly interesting discoveries have recently been made in regard to a double role played by the sting of the honey-bee. These discoveries explain some hitherto inexplicable phenomena in the domestic economy of the ants. It is already known that the honey of our honey-bees, when mixed with a tincture of litmus, shows a distinct red color, or in other words has an acid reaction. It manifests this peculiarity because of the volatile formic acid which it contains. This admixed acid confers upon crude honey its preservative power. Honey which is purified by treatment with water under heat, or the so-called honey-syrup, spoils sooner, because the formic acid is volatilized. 'The honey of vicious swarms of bees is characterized by a tart taste and a pungent odor. This effect is produced by the formic acid, which is present in excess in the honey. Hitherto it has been entirely unknown in what way the substratum of this peculiarity of honey, the formic acid in the honey, could enter into this vomit from the honey-stomach of the workers. Only the most recent investigations have furnished us an explanation of this process. The sting of the bees is used not only for defense but quite principally serves the important purpose of contributing to the stored honey an

\footnotetext{
* Translated from an article entitled "Ueber eine doppelrolle des stachels der honigbienen" in Deutsch. amerikanische apotheker-zeitung, 15 Jan. 1885, jahrg. 5, p. 664 ; there reprinted from "Ind. blatter."
}

antizymotic and antiseptic substance. The observation has recently been made that the bees in the hive, even when they are undisturbed, wipe off on the combs the minute drops of bee-poison (formic acid) which from time to time exude from the tip of their sting. And this excellent preservative medium is thus sooner or later contributed to the stored honey. The more excitable and the more ready to sting the bees are, the greater will be the quantity of formic acid which is added to the honey, and the admixture of which good honey needs. The praise which is so commonly lavished upon the Ligurian race of our honey bees, which is indisposed to sting-and such praise is still expressed at the peripatetic gatherings of German bee-masters - is therefore from a practical point of view a false praise. Now we understand also why the stingless honey-bees of South America collect little honey. It is well known that never more than a very small store of honey is found in felled trees inhabited by stingless Melipona. What should induce the Melipona to accumulate stores which they could not preserve?! They lack formic acid. Only three of the eighteen different known species of honey-bees of northern Brazil have a sting. A peculiar phenomenon in the life of certain ants has always been problematical but now it finds also its least forced explanation. It is well known that there are different grain-gathering species of ants. The 
seeds of grasses and other plants are often preserved for years in their little magazines, without germinating. A very small red ant, which drags grains of wheat and oats into its dwellings, lives in India. 'These ants are so small, that eight or twelve of them have to drag on one grain with the greatest exertion. They travel in two separate ranks over smooth or rough ground, just as it comes, and even up and down steps, at the same regular pace. They often have to travel with their booty more than a thousand metres, to reach their communal store-house. The renowned investigator Moggridge repeatedly observed that when the ants were prevented from reaching their magazines of grain, the seeds began to sprout. The same, was the case in abandoned magazines of grain. Hence the ants know how to prevent the sprout. ing of the grains, but the capacity for sprouting is not destroyed. The renowned English investigator John Lubbock, who communicates this and similar facts in his work entitled "Ants, bees and wasps," adds that it is not yet known in what way the ants prevent the sprouting of the collected grains. But now it is demonstrated that here also it is only the formic acid whose preservative influence goes so far that it can make seed incapable of germination for a determinate time or continuously.

It may be mentioned that we have also amongst us a species of ant which lives on seeds and stores these up. This is our Lasius niger, which carries seeds of Viola into its nests, and, as Wittmack has communicated recently to the Sitzungsberichte der gesellschaft naturforschender freunde zu Berlin, does the same with the seeds of Veronica hederaefolia.

Syke states in his account of an Indian ant, Pheidole providens, that this species collects a great store of grass-seeds. But he observed that the ants brought their store of grain into the open air to dry it after the monsoon storms. From this it appears that the preservative effect of the formic acid is destroyed by great moisture, and hence this drying process. So that amongst the bees the honey which is stored for winter use, and among the ants the stores of grain which serve for food, are preserved by one and the same fluid, formic acid.

\section{EDITORIAL NOTW.}

This same theory has been suggested many times by our most advanced American bee keepers. It has been hinted that this same formic acid was what made honey a poison to many people, and that the sharp sting of some honey, notably that from bass wood or linden, originated in this acid from the poison sack. If this is the correct explanation, it seems strange that the same kind of honey is always peculiar for greater or less acidity as the case may be. We often see bees with sting extended and tipped with a tiny drop of poison; but how do we know that this poison is certainly mingled with the honey? Is this any more than a guess? A. J. Cook. 

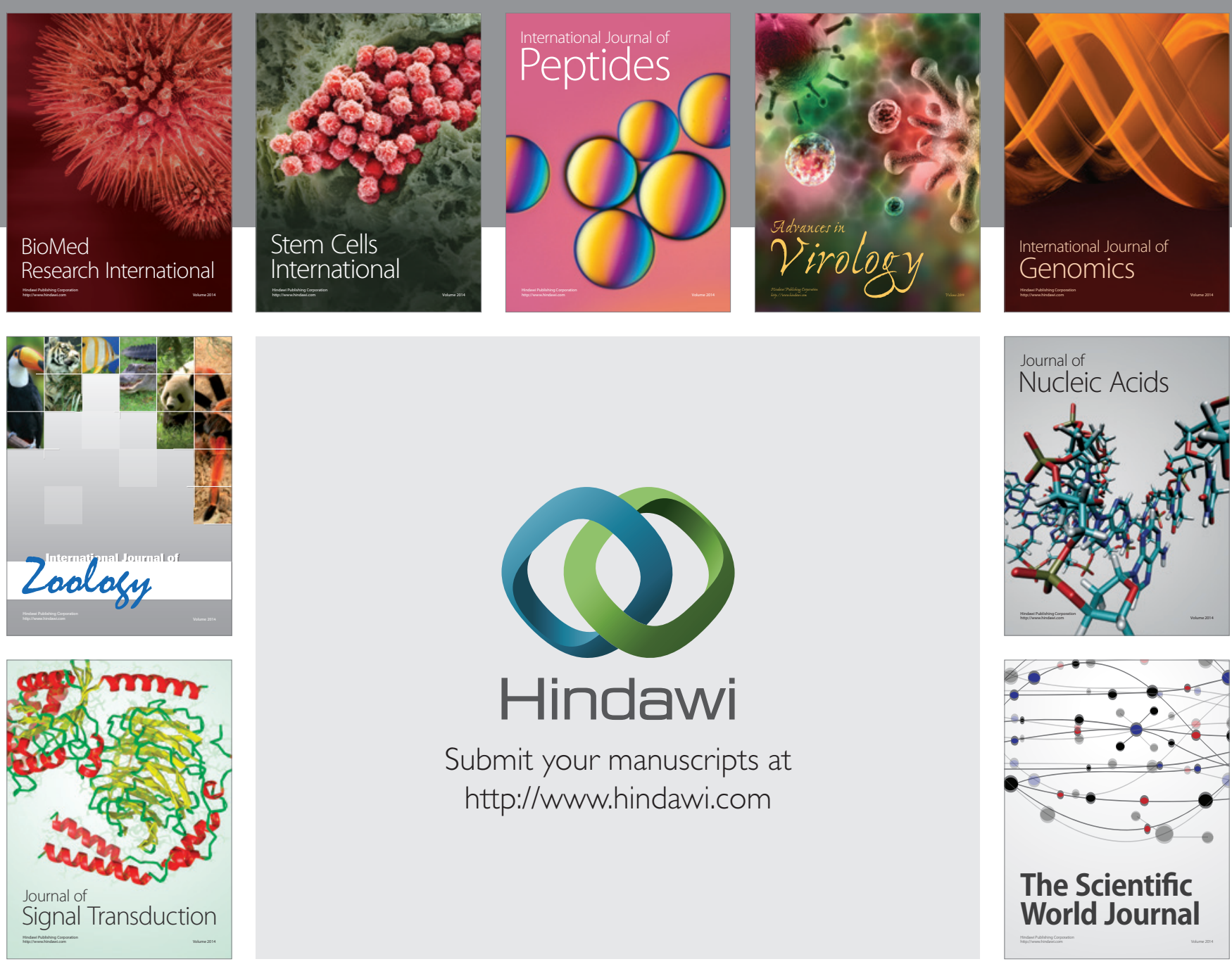

Submit your manuscripts at

http://www.hindawi.com
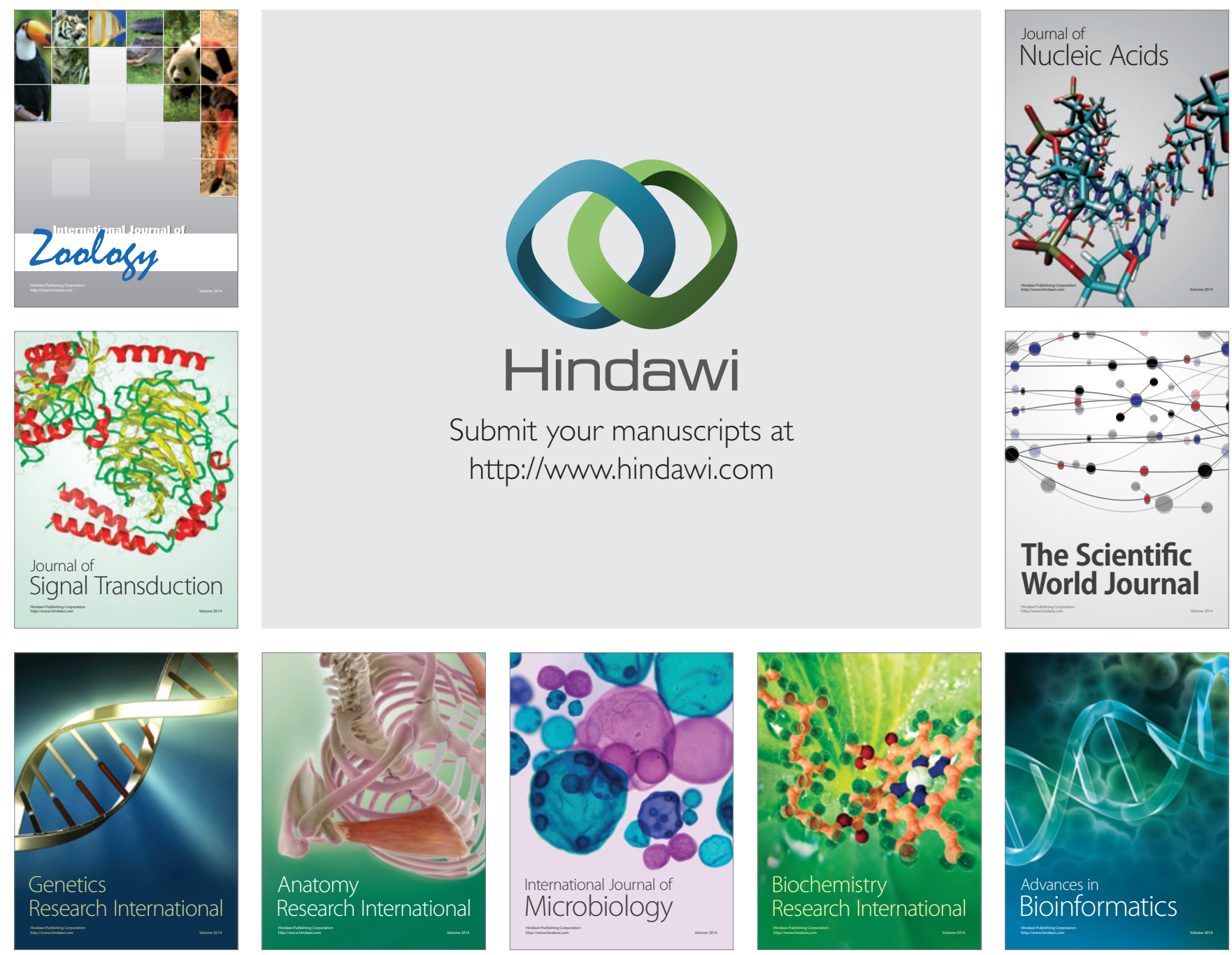

The Scientific World Journal
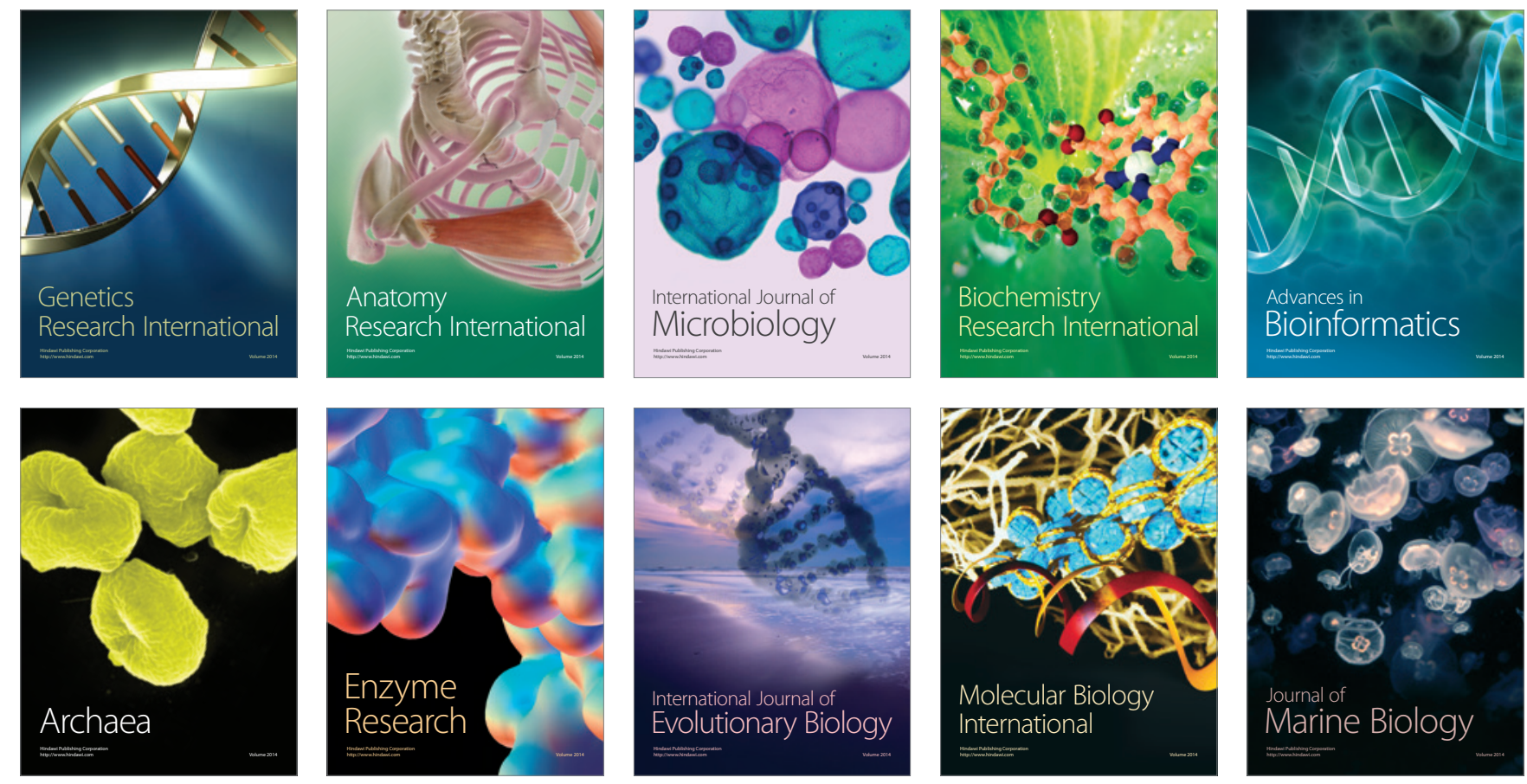